\title{
Introducing Storytelling to Educational Robotic Activities
}

\author{
Julian M. Angel-Fernandez \\ Automation and Control Institute \\ Vienna University of Technology \\ Vienna, Austria \\ Email: Angel-Fernandez@acin.tuwien.ac.at
}

\author{
Markus Vincze \\ Automation and Control Institute \\ Vienna University of Technology \\ Vienna, Austria \\ Email: Vincze@acin.tuwien.ac.at
}

\begin{abstract}
Creativity is a skill that has been recognized as one of the $21^{\text {st }}$ century skills. Likewise robotics has been recognized as technology with several features to enthrall children and be used to teach a variety of topics (e.g. Mathematics and programming). This paper presents a study done to verify the impact of introducing a storytelling session in an activity with children from 6 to 18 years old in Austria. A total of 196 participants participated in the workshops, held in the campus of the university. Quantitative and qualitative data were collected and analyzed. The results showed that the most difficult task for old participants was the collaboration between groups created. Participants also did not mention the use of creativity during the design and implementation of the story. Instead participants referred to the work done with robots and technology. Moreover, participants think that working with robots is interesting and fun.

Index Terms-Storytelling, Creativity, Robotics, Educational Robotics, Informal Education, Thymio II
\end{abstract}

\section{INTRODUCTION}

Creativity is a concept use to describe a person with certain features, mainly related to artistic fields. Nevertheless, it has been recognized as one of the $21^{\text {st }}$ century skills because a creative person is expected to generate new useful ideas, come with imaginative solutions and use diverse techniques to come with them [1]. It is important to notice that the interpretation of novel and useful is going to be given by the social context [2]. More important creativity has been recognized as essential element of problem solving and critical thinking [2], [3].

On the other hand, robotics has been used in education to teach diverse areas of knowledge such us physics [4], mathematics [5], programming [6] and soft skills [7]. Stager used a constructionism approaches to implement three different activities [8]: ballerina, teddy bear and Phonograph. Although he did not create these activities to foster creativity, they show how through robotics children can use their imagination to come with solutions to problems that are relevant to them. Considering the importance of creativity and the potential of robotics to foster thinking skills, process skills, and social interaction [9], it was decided to create an activity with robotics that could foster creativity in the frame of the European project Educational Robotics for STEM (ER4STEM).

This paper presents a study done to verify the impact of introducing a storytelling session in an activity with children from 6 to 18 years old in Austria. A total of 9 workshops were implemented in the university campus, with a total of 196 participants. Each workshop was implemented by two master students, who did not have any previous experience on education. Quantitative and qualitative data were collected and analyzed. The results showed that the most difficult task for old participants was the collaboration between different groups created. Participants also did not mention the use of creativity during the design and implementation of the story. Instead participants referred to the work done with robots and technology. Moreover, participants think that working with robots was interesting and fun.

This paper is organized as follows. Section II presents relevant work in educational robotics. Section III presents the definition of creativity and the mechanisms to foster it. Section IV introduces Thymio II, the platform used in the workshops, and the programming languages available for it. Section V presents the activity designed and section VI describes how the study was done. Finally, section VII presents the results obtained from all workshops and section VIII presents conclusion and further work.

\section{RELATED WORK}

Robotics has been used in different settings and platforms. Sullivan and Bers studied how robotics and computer programming could be used from pre-kindergarten to second grade classrooms and what children could learn from them [10]. They developed an eight week curriculum focused on teaching foundations of robotics and programming concepts. The robotic platform KIWI was used, which was specifically designed for young children (four years and up). The main particularties of KIWI are that it could be programmed using the Creative Hybrid environment for computer Programming (CHERP) and it does not require any computer to be programmed [11]. Similarly, Stoeckelmayr et al. [12] created eight workshops to introduce robotic concepts to kindergarten students using BeeBot.

However, the use of robotics is not limited to introduce robotics, it has been also used to teach physics and mathematics. For example Church et al. [13], Ashdown and Doria [4], and Williams et al. [14] have created activities to foster knowledge in physics using Lego Mindstorms platforms. Their results suggest that participants engaged with the activity and 
they learned about the topic that was evaluated. Stager used a constructionism approaches to implement three different activities [8]: ballerina, teddy bear and Phonograph. Each activity was implemented with diverse groups and robotic platforms with different time span. Although he did not create these activities to foster creativity, they show how through robotics children can use their imagination to come with solutions to problems that are relevant to them.

In the last decade, researchers have come with the idea of using social robots in schools. Some researchers have investigated the features that a robot should have when is placed in a classroom [15]. They identified that motion is important for the participants, because it helps to break the monotony of classroom. Moreover participants highlight the importance of visualising geometrical concepts in the real world and their interest in interacting with the robot in pet-like way. Other researchers focused on the impact of verbal cues given by a robot to participants [16], suggesting that it has a positive impact. Nevertheless, their research is focused on the social aspects of autonomous robots instead of the correct use in education.

Despite the versatility of robotics in terms of topics, ages and situations, there is required to understand their correct use in education. Without this understanding the real potential of robotics in education will not be completely unleash and in some situation could jeopardize the learning experience [17].

\section{CReativity}

Creativity is an abstract concept that everyone uses but when they are asked to define its meaning they struggle to come with a precise and clear definition. More important, most people link creativity with artistic creations, neglecting its presences in other fields. Nevertheless, creativity has been acknowledged as an important factor of competiveness in modern organizations [18]. Despite its importance, there is not a unify definition of creativity [19], [20] and it could vary depending on the field and researcher. Nevertheless, there are common characteristics among definitions, which could slightly differ on terminology. Therefore, researchers tend to define creativity as the ability to come with ideas or products that are novel and useful [19]. It is important to notice that the interpretation of novel and useful is going to be given by the social context [2].

Although creativity could happen naturally in many cases, the creation of environments that promotes creativity is also possible. The following are characteristics identified to promote individuals' creativity:

- Definition of clear goals [21].

- Balance between knowledge and challenge [20], [21].

- Creation of a climate where students are not fear about failure [18], [20], [21].

- There not should be competitions or rewards after finishing [20].

- Motivate students to be creative [2].

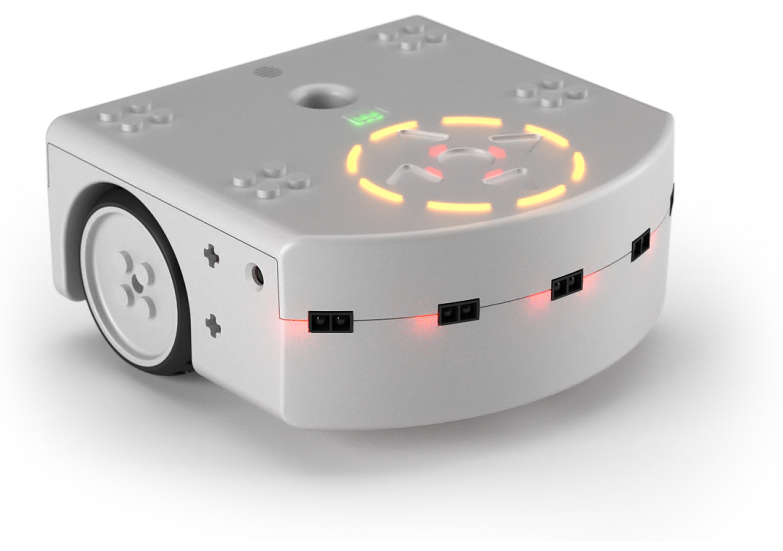

Fig. 1. Educational platform Thymio II.

\section{THYміо II}

Thymio II is an educational robotic platform created at EPFL (Figure 1) [22]. It has several characteristics that make it appealing to our purposes. First, Lego blocks could be connected to the robot. Second, the robot has several infrared sensors, a speaker, four push buttons, one microphone and lights. Moreover it offers three different programming languages that could be used through their IDE called ASEBA:

- Visual programming was designed to let users drag and drop components into a canvas in Aseba studio. Figure 2a shows the programming interface. As it could be observed, the user can select from events (right) and combine with actions (left).

- Blockly programming is the Scracth [23] version for Thymio II. As it could be seen in the Figure 2-b, it provides several components, such as conditionals or variables.

- Text programming is a programming language created for Thymio II. Figure 2-c presents an example of a program that reacts when an object is approaching.

\section{THE ACTIVITY}

The activity was created with the objective to introduce basic programming and foster creativity in the participants. It was assumed that participants do not have any previous knowledge in robotics or programming. To provide participants with necessary knowledge to implement the story, the activity was divided in two sessions. The first session focus on letting participants to get familiar with the robot and introducing them basic programming concepts. This is achieve through the following exercises:

1) Measurements with Thymio is aimed to expose children with the robot and introduce basic concepts of robotics. During this exercise, children are asked to fill a table with the values obtained from Thymio's sensors. In this 


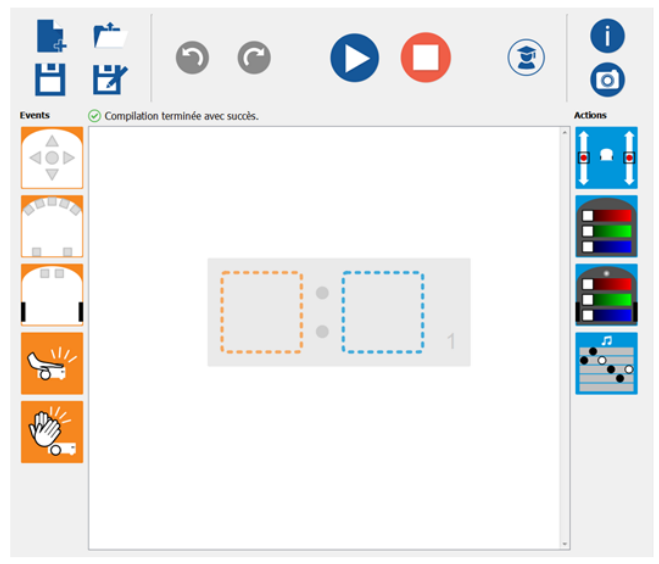

a)

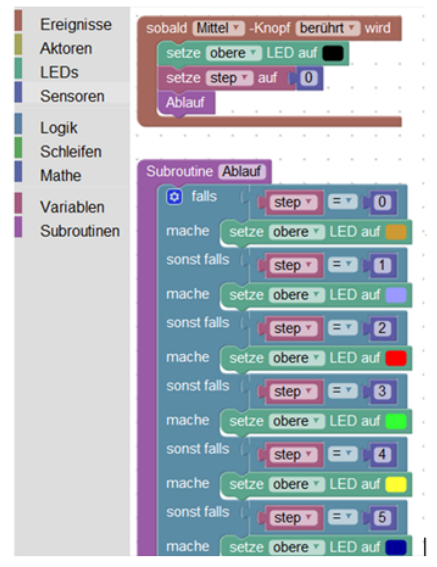

b)

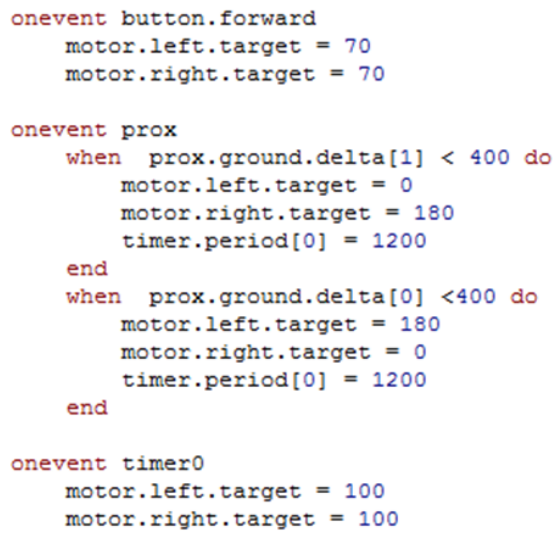

c)

Fig. 2. Programming languages available in Aseba Studio. a) Visual programming. b) Blockly programming. c) Text programming.

way they can get a better idea on how the values change depending on the situation.

2) Drive through maze aims to make evident the sequential thinking behind programming. Children' task is to program the robot to go out a simple maze.

3) Start-stop event introduces the concept of events in programming. Children must use the five push buttons to trigger an event, which corresponds to the direction that the robot has to move.

4) Stop at table's edge is an extension of the previous exercise to prevent the robot fall down the table. This could help children to delimit the zone where the robot has to move.

5) Avoid obstacles aims to let the robot to move autonomously while avoiding any obstacle that could find in its way.

6) Reach the point introduces children to timer function. As its name suggest, this function triggers an event once the time set has been reached. Therefore participants have to play with this time to make the robot move forward to reach a specific point.

For each one of these exercises is provided a handout with the following structure: a general description, which includes the goal of the exercise, the tasks description and some tips that could be useful for the students. An example of a handout is presented in Figure 3.

The second session focus on the storytelling. Before starting, the group is asked to create two big groups, each group will create their own story. Once the groups are created, they are asked to create three sub-groups, which will focus on different aspects of the implementation. One group will be the designers, who are in charge to create the story and all the props for the story. The second is the technicians, who will implement the story with the robots. Finally, the directors group has to coordinate the work within the other two groups. The stories are advised to be written in a way that could take advantage of the knowledge gained in the previous session.
Exercise 6: Finishingstraight

Introduction: Goal

The goal of this exercise is to get to know the use of Thvmio's timer. A timer works quite similar to the countdown before a race: The referee counts down, starting at a specific number (e.g. five): $5-4-3-2-1-$ and at zero the race starts. Likewise you can set the time of Thymio's timer to a specific number and after expiry of that time the robot makes some action. General description

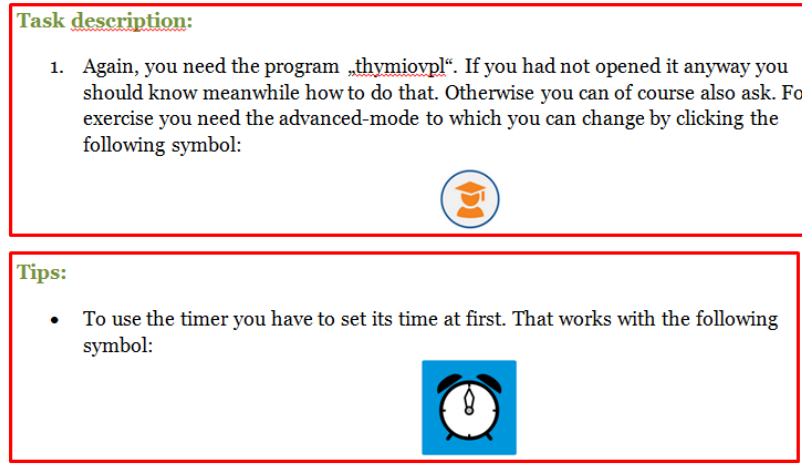

Fig. 3. Example of the handout provided to the participants highlighting the three main parts: general description, task description and tips.

Moreover the following constraints are added:

- The video must not be longer than one minute and has to be less than 40 seconds. This constrains adds the difficulty that designers and technicians must communicate to consider robots movements, such as speed and how much actions could be done during this period of time.

- Each group must record their story but there is just one camera for both groups. So there must be a coordination also between them.

- The video has to include at least two robots.

- The human intervention must be reduced to the minimum.

Finally, the children are asked to prepare a short presentation where they reflect their experiences and problems they faced during the second session. To do this, participants are provided with a template, which includes specific questions about team work and their learning experience. 


\section{THE STUDY}

The evaluation kit developed in ER4STEM was used to collect quantitative and qualitative data [24]. This evaluation kit was developed with the objective answer ER4STEM's research questions, which are focus on maintain the interest of children in technology and STEM. The evaluation kit has the following components:

- Handling protocol, which describes precisely how to use the evaluation material.

- Pre and post activity questionnaires that collects personal information, past experience and existing attitudes towards STEM. This helps to evaluate the impact of the workshop on the participants.

- Draw-a-scientist provides an understanding on previous stereotypes of the participants towards scientist.

- Observations of tutors are comments provided by the tutors that they consider of relevance and that occurred during the workshop. These comments help to inform the late analysis of the data.

- Interview questions and protocol defines the way the data is collected, stored and shared.

- Students reflections and artifacts of their learning are collected and used also to verify the impact of the workshop.

- Tutor reflection is a set of questions that are answered by the tutors after each workshop.

- Inform consent documents, which provides relevant information to parents and participants about the research done during the workshops.

- Reporting templates establish the basic structure on how the information is reported.

\section{A. Questionnaires}

A Pre and post activity questionnaires are used to collect quantitative information. The pre-questionnaire captures participants' attitudes towards STEM subjects and careers. It is composed of:

- One multiple option question about the languages spoken at home.

- One question about previous experience in robotics and programming.

- 39 Liker questions about attitude towards technology, mathematics and science.

- Two multiple option questions regarding participants' favorite and least favorite subjects with their corresponding justification.

- Two yes/no question two know if they would like to study science or maths.

On the other hand, the post-questionnaire aims to determine learners' experience in the workshop and their future intentions. Therefore it is compose of:

- Six Likert questions about the problems solved, working with robots, and working in a team.

- Two multiple option question about the knowledge used and acquired during the workshop.
- 16 Likert questions about participants' perception of the activity (e.g. "During the workshop I was bored")

- Three open questions about what they have learned about their selves, working with other people and about robots.

- 16 check questions about change of attitudes towards science and math after the workshop.

- Rate the workshop with its corresponding justification.

Young participants, 6 to 10 year old, could struggle with these long questionnaires and with the meaning of some of the questions. Therefore a lighter version of these two questionnaires was generated. Some questions were rephrase to make it easy to understand and some questions were removed such us "working with robots I have used my knowledge of..." and "working with robots I have learned about...". The questionnaires used with young participants are later refer as type one, while the one for old as type two.

\section{B. Procedure}

The preparation of each workshop starts one to two months before the actual workshop take place. Participants are provided in advance with the consent forms and draw-a-scientist that they must bring at the day of the workshop. In the day of the workshop, two tutors receive the participants at the entrance of the engineering building and accompany them to the computer room. These tutors are master students hired to implement the workshops and do not have previous experience in teaching. Their presence during the workshop is to support participants when any problem or question is raised by the participants. Once the participants arrive to the computer room, the tutors collect the consent forms and provide them a number tag to anonymize their identities. This number is assigned in advance. Then it is done the pre-questionnaire, in which participants introduce their code number. Once all participants have finished the pre-questionnaire, the tutors ask them to form groups of 2 or 3 people. From all the groups, it is designated one as a focus group, which all members agreed on the consent form to be recorded. The tutors provide them a GoPro camera, which they can use to register what they considered as relevant.

With all in order, the tutor give to the participants handouts with the first exercise. Every time one group completes the exercise a new handout is provided. Ideally the first session last three hours, including the time required for the prequestionnaire, and the second session occurs another day. However no all groups could come twice. In this case, a break of 15 minutes is done to let participants relax. The second session starts asking participants two create two groups. Once they are in their groups the whole activity is explained, including the restrictions for the video. When everything has been setup, the tutor provide each group with two robots and a kit of Lego blocks. During the whole session the two tutors are present to answer any questions or help the participants in case of difficulties. 30 minutes before the end of the workshop, the focus group is interviewed; the interview takes around 10 minutes. When they come back, they are asked to fill the postquestionnaire. 


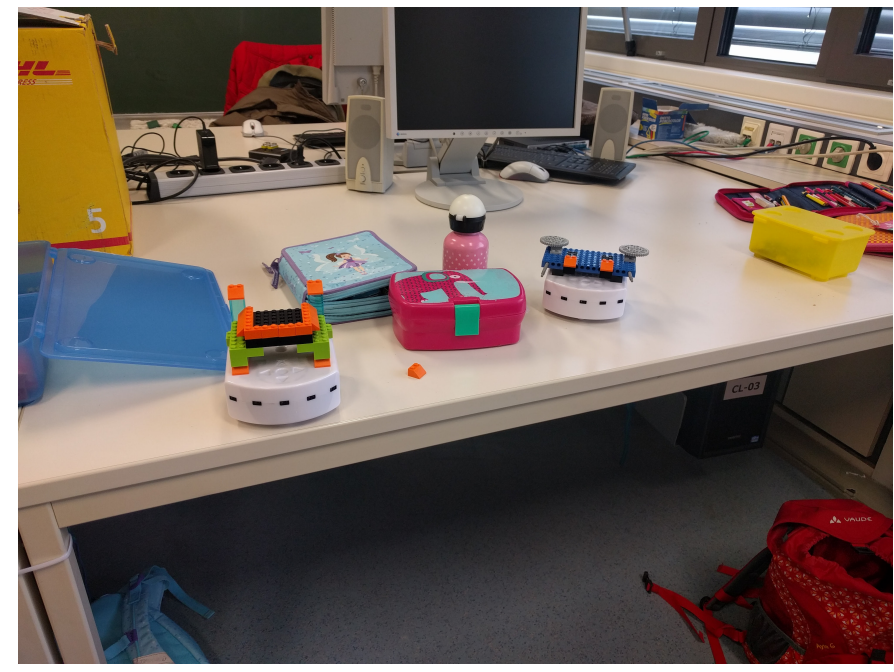

Fig. 4. Example of the robots created by the participants during the storytelling session.

\section{RESULTS}

Table I presents the information of the groups that participated. This information includes age, number of gender, programming language used during the intervention, number of sessions and stars given to the workshop. Different programming language was used depending on the group age. For example VPL was used with young groups while textual and blocky with the older ones. Some of the groups did not manage to answer all of the questions (i.e. 2017-01-26 and 2017-01-31) or to do the post-questionnaires (i.e. 2017-06-13) due to time restrictions. Moreover, just with one group was possible to have the final presentation.

The difference in the number of sessions is due some groups could not come twice. In order to solve this, longer session were done. This have impacted the number of stars given to the workshop due to, among other things, the short time to design and implement the story. Nevertheless, the number of stars given by the young participants is much higher than the ones given by the older ones.

Figure 4 presents the robots created by one of the groups during the storytelling session. It could be observed how participants used Lego blocks and its colors to change the aspect of the robots.

\section{A. Qualitative Analysis}

The qualitative analysis showed that old participants had difficult collaborating during the storytelling part. In fact, during the interview to the focus groups 2017-06-13, 2017-02-02 and 2017-03-30, they mentioned their difficulty to collaborate in big groups. This should not be a surprise if it is considered that collaboration is a skill that must be learned [25] and it is not taught in school. On the other hand, young participants struggle with programming, such as it was mentioned during the interviews with the focus groups 2017-01-26 and 201703-06. Interestingly one interviewee of the group 2017-0126 suggested that math could be helpful in programming.
This is surprising because it was not done any mention to mathematics done during any workshop. It was also found possible culture-technology stereotypes during the interview to the focus group 2017-01-31, where the interviewee suggested that robots in Japan are more advance because there "robots are saving people from burning buildings". This is really interesting considering that the kid was only seven years old.

Given the short time and the limited skill of young participants on writing and reading, it was difficult to get answers to the open questions in the post-questionnaire. Therefore, it was just obtained answers from old participants. The qualitative results show that groups 2017-02-01, 2017-02-02, 2017-0330 had fun, were interested and learned a lot. On the other hand, some participants from 2017-02-01 wrote that they felt frustrated and don't like when things did not work the way they were expecting. This could be explained in the expectations that traditional education systems create on children, making them think that all problems have a unique solution. Unexpectedly, other participants from the groups 2017-02-01 and 2017-03-30 stated that they were bored and the activity was difficult.

From tutors' observation and reflection, it was identified that they think participants do not understand the easily the work flow of a program. There is also stated that just workshop 2017-02-01 and 2017-02-23 participants collaborated well. Indeed, the interviewees from the group 2017-02-23 mentioned. Something that was unexpected was the fact that during the workshop 2017-03-30 tutors had to change from textual programming to blockly because some participants attended to the workshops offered in the previous year, where they used blocky. This event and the fact that the handouts prepared by the tutors were done for textual programming could explain why some of the participants fell frustrated and bored. Also it is interesting to consider participants' unwillingness to try a new programming language even when the whole explanation was provided in the handouts.

\section{B. Quantitative Analysis}

Table II presents the number of participants who have created a robot and/or programmed before. The number of participants who have created a robot before $(33 \%)$ is lower that the number of participants who have programmed (45\%). In both cases the predominant place has been a Club/Workshop, with a significant number of participants who have done it at home. It is important to observe that most of the participants of group 2017-02-23 have created a robot at school. Also it is possible to observe that two older groups have mainly done activities in clubs/workshop with limited experience at school.

The answers to the questions present in both prequestionnaires are presented in Figure 5. Most of the participants like using computers. The only exception is found in the group 2017-02-23, where half of the participants agree and strongly agree, one fourth of the participants are neutral and the rest are disagree and strongly disagree. Most of the participants tend to consider that they do not know a lot of robots, with some groups tending to be neutral. To the 
TABLE I

NUMBER OF PARTICIPANTS PER CLASS, GENDER, AGE, TYPE OF QUESTIONNAIRE USED, PROGRAMMING LANGUAGE, NUMBER OF SESSION AND STARS GIVEN TO THE WORKSHOP.

\begin{tabular}{|c|c|c|c|c|c|c|c|c|c|c|c|c|}
\hline \multirow{2}{*}{ Class ID } & \multicolumn{2}{|c|}{ Number of Answers } & \multicolumn{2}{|c|}{ Gender } & \multicolumn{4}{|c|}{ Age } & \multirow{2}{*}{$\begin{array}{l}\text { Questionnaire } \\
\text { Type }\end{array}$} & \multirow{2}{*}{$\begin{array}{l}\text { Programming } \\
\text { Language }\end{array}$} & \multirow{2}{*}{$\begin{array}{l}\text { Number of } \\
\text { Sessions }\end{array}$} & \multirow{2}{*}{ Stars } \\
\hline & Pre & Post & Female & Male & Mean & $\sigma$ & Min. & Max. & & & & \\
\hline $2017-01-26$ & 23 & 23 & 15 & 8 & 6.6 & 0.5 & 6 & 7 & 1 & VPL & 2 & 4.65 \\
\hline $2017-01-31$ & 20 & 21 & 8 & 12 & 6.45 & 0.51 & 6 & 7 & 1 & VPL & 2 & 4.71 \\
\hline $2017-02-01$ & 23 & 23 & 17 & 6 & 13.57 & 0.51 & 13 & 14 & 2 & VPL & 1 & 3.68 \\
\hline $2017-02-02$ & 12 & 12 & 6 & 6 & 13.5 & 0.67 & 13 & 15 & 2 & Textual & 1 & 3.92 \\
\hline $2017-02-23$ & 19 & 18 & 11 & 8 & 8.68 & 0.75 & 8 & 10 & 1 & VPL & 2 & 4.61 \\
\hline 2017-03-06 & 22 & 19 & 9 & 13 & 8.22 & 1.26 & 6 & 10 & 1 & VPL & 2 & 4.82 \\
\hline $2017-03-30$ & 19 & 18 & 7 & 12 & 15.05 & 1.18 & 14 & 18 & 2 & Blockly & 1 & 3.63 \\
\hline 2017-04-19 & 19 & 19 & 10 & 9 & 9.63 & 0.68 & 9 & 11 & 1 & Blockly & 2 & 4.37 \\
\hline $2017-06-13$ & 25 & NA & 11 & 14 & 14.8 & 0.5 & 14 & 16 & 2 & Textual & 2 & NA \\
\hline Total & 182 & 153 & 94 & 88 & 10.7 & 3.4 & 6 & 18 & NA & NA & NA & 4.32 \\
\hline
\end{tabular}

TABLE II

NUMBER OF PARTICIPANTS THAT HAVE CREATED A ROBOT AND/OR PROGRAMMED BEFORE.

\begin{tabular}{|c|c|c|c|c|c|c|c|c|}
\hline \multirow{2}{*}{ Class ID } & \multicolumn{4}{|c|}{ Have you created a robot before? } & \multicolumn{4}{|c|}{ Have you programmed before? } \\
\cline { 2 - 5 } & \multirow{2}{*}{ Yes } & \multicolumn{3}{|c|}{ Where? } & \multicolumn{3}{|c|}{ Where? } \\
\cline { 3 - 5 } \cline { 7 - 9 } & & Club/Workshop & Home & School & & Club/Workshop & Home & School \\
\hline $2017-01-26$ & 2 & 1 & 0 & 2 & 19 & 17 & 0 & 0 \\
\hline $2017-01-31$ & 5 & 1 & 0 & 4 & 4 & 1 & 1 & 2 \\
\hline $2017-02-01$ & 14 & 0 & 14 & 1 & 13 & 0 & 13 & 1 \\
\hline $2017-02-02$ & 6 & 0 & 5 & 2 & 8 & 0 & 4 & 5 \\
\hline $2017-02-23$ & 14 & 12 & 0 & 2 & 5 & 0 & 1 & 4 \\
\hline $2017-03-06$ & 1 & 0 & 0 & 1 & 0 & 0 & 0 & 1 \\
\hline $2017-03-30$ & 3 & 1 & 2 & 0 & 18 & 1 & 18 & 3 \\
\hline $2017-04-19$ & 2 & 1 & 1 & 1 & 4 & 3 & 0 & 0 \\
\hline $2017-06-13$ & 14 & 0 & 10 & 5 & 11 & 7 & 3 & 2 \\
\hline Total & $\mathbf{6 1}$ & $\mathbf{1 6}$ & $\mathbf{3 2}$ & $\mathbf{1 8}$ & $\mathbf{8 3}$ & $\mathbf{2 9}$ & $\mathbf{4 0}$ & $\mathbf{1 8}$ \\
\hline
\end{tabular}

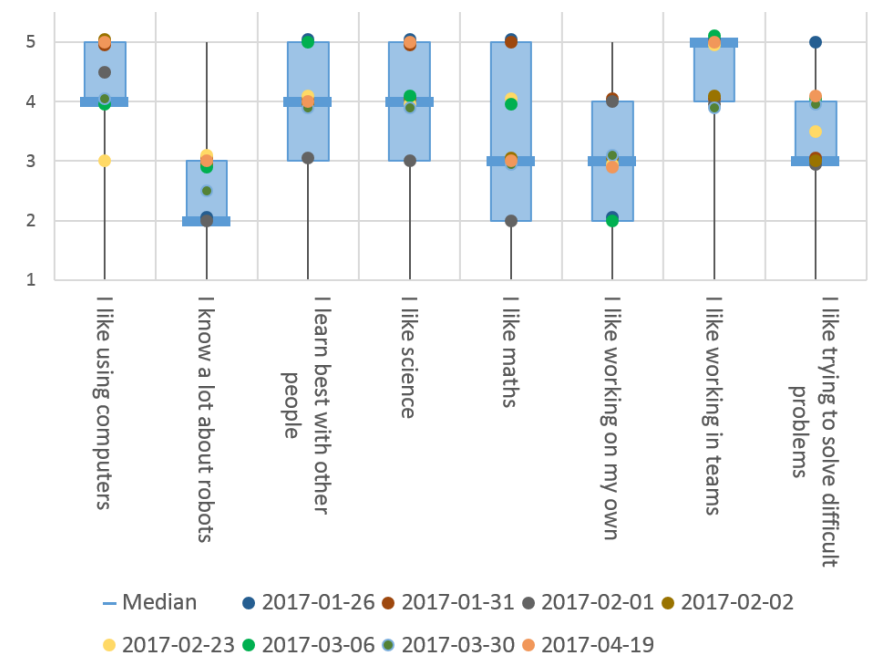

Fig. 5. Box plot of the answers obtained in the Likert scale questions in the pre-questionnaire that are shared in questionnaires type 1 and 2 . The dots symbolize the median of each group. 1 is strongly disagree and 5 strongly agree.

questions "I learn best with other people" and "I like science" most of the participants agree or strongly agree. It is important to notice that most participants strongly agree to the question "I like working in teams".

Figure 6 presents the results to the post questionnaire questions in both post-questionnaires. It is interesting to ob- serve that more than $50 \%$ of the participants considered that was interesting and fun working with robots. Likewise they considered the problems solved as interesting and fun. This is also reflect in the question "I was bored", in which more than a half of the participants disagree and strongly disagree. It is important to highlight that participants considered that they work as a part of a team and they did not worked alone.

The answers to the questions related to working with robots I have used my knowledge of... and has helped me to learn more about... are reported in Table III. These two questions were not asked in post-questionnaire type one. Most of the participants considered that they used your knowledge of technology and how thing works. Likewise participants stated that they have learned about technology and how things work. A chi test was done for each question to determine if there was any difference between genders. The results showed that there is no difference between genders $(p>(\alpha=0.05))$ in all the questions.

\section{CONCLUSION AND FURTHER WORK}

Creativity is a skill that been recognized as essential element of problem solving and critical thinking [2], [3]. At the same time, these last two skills are soft skills that are wanted by the industry. With the objective to understand if robotics could be used to foster creativity, it was presented the inclusion of a storytelling session in a robotics activity with children between 6 to 18 years old in Austria. A total of 9 workshops were implemented in the university campus, with a total of 196 participants. Quantitative and qualitative 


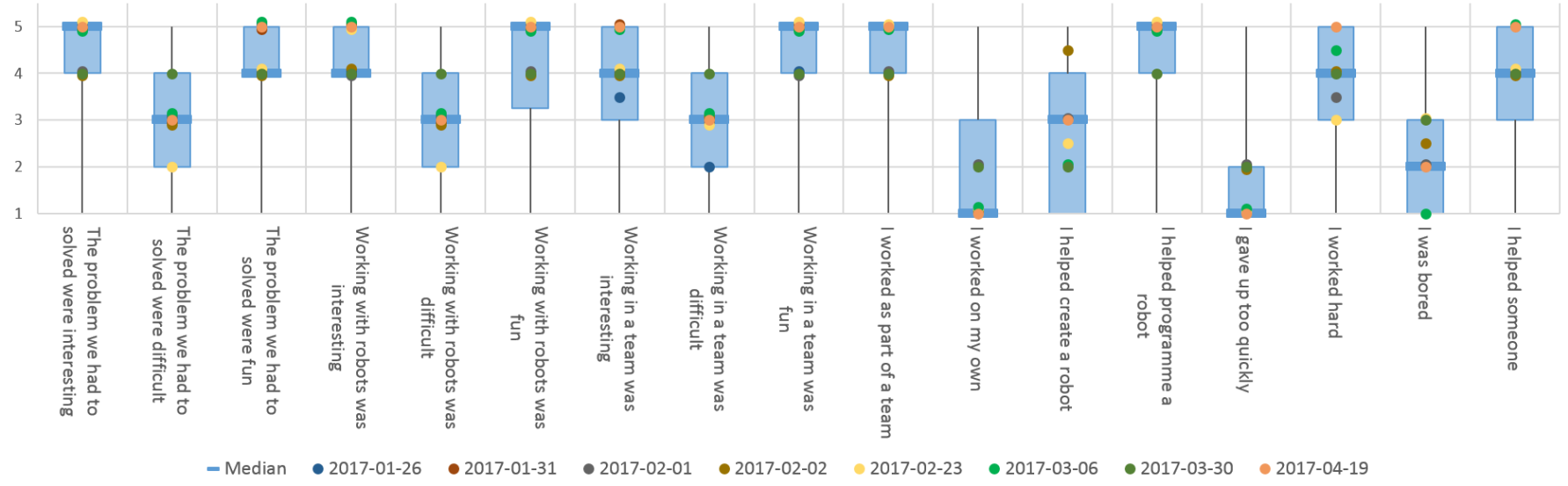

Fig. 6. Box plot of the answers obtained in the Likert scale questions in the post-questionnaire that are shared in questionnaires type 1 and 2 . The dots symbolize the median of each group. 1 is strongly disagree and 5 strongly agree.

TABLE III

NUMBER OF PARTICIPANTS WHO BELIEVED THAT WORKING WITH ROBOTS THEY USED THEIR KNOWLEDGE OF... AND THEY LEARN MORE ABOUT ...

\begin{tabular}{|c|c|c|c|c|}
\hline Question & Topic & Gender & Number & Total \\
\hline \multirow{10}{*}{$\begin{array}{l}\text { Working with } \\
\text { robots I have } \\
\text { used my } \\
\text { knowledge of ... }\end{array}$} & \multirow{2}{*}{ Science } & Female & 5 & \multirow{2}{*}{6} \\
\hline & & Male & 1 & \\
\hline & \multirow{2}{*}{ Technology } & Female & 25 & \multirow{2}{*}{43} \\
\hline & & Male & 18 & \\
\hline & \multirow{2}{*}{ Art } & Female & 3 & \multirow{2}{*}{4} \\
\hline & & Male & 1 & \\
\hline & \multirow{2}{*}{ How things work } & Female & 18 & \multirow{2}{*}{36} \\
\hline & & Male & 18 & \\
\hline & \multirow{2}{*}{ Maths } & Female & 10 & \multirow{2}{*}{18} \\
\hline & & Male & 8 & \\
\hline \multirow{9}{*}{$\begin{array}{l}\text { Working with } \\
\text { robots has } \\
\text { helped me to } \\
\text { learn more } \\
\text { about ... }\end{array}$} & \multirow{2}{*}{ Science } & Female & 2 & \multirow{2}{*}{3} \\
\hline & & Male & 1 & \\
\hline & \multirow{2}{*}{ Technology } & Female & 26 & \multirow{2}{*}{44} \\
\hline & & Male & 18 & \\
\hline & Art & Female & 0 & 1 \\
\hline & \multirow[b]{2}{*}{ How things work } & $\begin{array}{l}\text { Male } \\
\text { Female }\end{array}$ & $\begin{array}{c}1 \\
19\end{array}$ & \multirow{2}{*}{32} \\
\hline & & Male & 13 & \\
\hline & \multirow{2}{*}{ Maths } & Female & 0 & \multirow{2}{*}{2} \\
\hline & & Male & 2 & \\
\hline
\end{tabular}

data were collected and analyzed. The results showed that the most difficult task for old participants was the collaboration between different groups. Participants also did not mention the use of creativity during the design and implementation of the story. Instead participants referred to the work done with robots and technology. Moreover, participants think that working with robots was interesting and fun. Paradoxically, participants did not considered that they used their creativity or their knowledge of arts during the creation of the story.

Although the participants did not realize the use of creativity during the design and implementation of the story, it was possible to observe the engagement of the participants during the activity and perhaps an unnoticed improvement in their creativity. Nevertheless, it is still required to extend the time of the activity to provide a better knowledge in programming and introduce participants to story design.

\section{ACKNOWLEDGMENTS}

This work is funded by the European Commission through the Horizon 2020 Programme (H2020, Grant agreement no: 665972). Project Educational Robotics for STEM: ER4STEM. This is a pre-copyedited version of a contribution published in IEEE EDUCON 2018. The definitive authenticated version is available online: https://doi.org/10.1109/EDUCON.2018.8363286

\section{REFERENCES}

[1] G. Burkhardt, M. Monsour, G. Valdez, C. Gunn, M. Dawson, C. Lemke, E. Coughlin, V. Thadani, C. Martin et al., "engauge 21st century skills: Literacy in the digital age," Retrieved June, vol. 2, p. 2008, 2003.

[2] R. L. DeHaan, "Teaching creativity and inventive problem solving in science," CBE-Life Sciences Education, vol. 8, no. 3, pp. 172-181, 2009.

[3] P. C. Abrami, R. M. Bernard, E. Borokhovski, A. Wade, M. A. Surkes, R. Tamim, and D. Zhang, "Instructional interventions affecting critical thinking skills and dispositions: A stage 1 meta-analysis," Review of Educational Research, vol. 78, no. 4, pp. 1102-1134, 2008.

[4] J. Ashdown and D. Doria, "A robotics based design activity to teach the doppler effect." in IEEE 2nd Integrated STEM Education Conference. IEEE, 2012.

[5] S. Hussain, J. Lindh, and G. Shukur, "The effect of lego training on pupils' school performance in mathematics, problem solving ability and attitude: Swedish data," Journal of Educational Technology \& Society, vol. 9 , no. 3, 2006

[6] D. Tochek, J. Lape, and V. Fuglk, "Developing technological knowledge and programming skills of secondary schools students through the educational robotics projects," Procedia - Social and Behavioral Sciences, vol. 217 , pp. 377 - 381, 2016.

[7] M. Kandlhofer and G. Steinbauer, "Evaluating the impact of educational robotics on pupils' technical- and social-skills and science related attitudes," Robot. Auton. Syst., vol. 75, no. PB, pp. 679-685, Jan. 2016.

[8] G. Stager, "A constructionist approach to teaching with robotics," in Proceedings of Constructionism and Creativity Conference, Paris, France, 2010, pp. 16-20.

[9] F. B. V. Benitti, "Exploring the educational potential of robotics in schools," Comput. Educ., vol. 58, no. 3, pp. 978-988, Apr. 2012.

[10] A. Sullivan and M. U. Bers, "Robotics in the early childhood classroom: learning outcomes from an 8-week robotics curriculum in prekindergarten through second grade," International Journal of Technology and Design Education, vol. 26, no. 1, pp. 3-20, 2016.

[11] A. Sullivan, E. R. Kazakoff, and M. U. Bers, "The wheels on the bot go round and round: Robotics curriculum in pre-kindergarten," Journal of Information Technology Education, vol. 12, 2013. 
[12] K. Stoeckelmayr, M. Tesar, and A. Hofmann, "Kindergarten children programming robots: a first attempt," Proc. Robotics in Education, pp. 185-192, 2011.

[13] W. J. Church, T. Ford, N. Perova, and C. Rogers, "Physics with robotics - using lego mindstorms in high school education." in AAAI Spring Symposium: Educational Robotics and Beyond. AAAI, 2010.

[14] D. C. Williams, Y. Ma, L. Prejean, M. J. Ford, and G. Lai, "Acquisition of physics content knowledge and scientific inquiry skills in a robotics summer camp," Journal of Research on Technology in Education, vol. 40, no. 2, pp. 201-216, 2007.

[15] E. Walker and W. Burleson, "User-centered design of a teachable robot," in International Conference on Intelligent Tutoring Systems. Springer, 2012, pp. 243-249.

[16] L. N. Brown and A. M. Howard, "The positive effects of verbal encouragement in mathematics education using a social robot," in Integrated STEM Education Conference (ISEC), 2014 IEEE. IEEE, 2014, pp. 1-5.

[17] J. Sharkey, "Establishing twenty-first-century information fluency," Reference \& User Services Quarterly, vol. 53, no. 1, p. 33, 2013.

[18] B. Scozzi, C. Garavelli, and K. Crowston, "Methods for modeling and supporting innovation processes in smes," European Journal of Innovation Management, vol. 8, no. 1, pp. 120-137, 2005.

[19] M. Batey, "The measurement of creativity: From definitional consensus to the introduction of a new heuristic framework," Creativity Research Journal, vol. 24, no. 1, pp. 55-65, 2012.

[20] T. Lewis, "Creativity: A framework for the design/problem solving discourse in technology education," Journal of technology education, vol. 17, no. 1, p. 36, 2006.

[21] M. Csikszentmihalyi, Flow and the psychology of discovery and invention. New York: Harper Collins, 1996.

[22] F. Riedo, P. Rétornaz, L. Bergeron, N. Nyffeler, and F. Mondada, A Two Years Informal Learning Experience Using the Thymio Robot. Berlin, Heidelberg: Springer Berlin Heidelberg, 2012, pp. 37-48.

[23] M. Resnick, J. Maloney, A. Monroy-Hernández, N. Rusk, E. Eastmond, K. Brennan, A. Millner, E. Rosenbaum, J. Silver, B. Silverman, and Y. Kafai, "Scratch: Programming for all," Commun. ACM, vol. 52, no. 11, pp. 60-67, Nov. 2009.

[24] C. Girvan, "Pre-kit for evaluation," Cardiff University, Tech. Rep., Febraury 2016.

[25] L. Goulet, C. Krentz, and H. Christiansen, "Collaboration in education: The phenomenon and process of working together," Alberta journal of educational research, vol. 49, no. 4, p. 325, 2003. 